\title{
Anabases
}

ANABASES Traditions et réceptions de l'Antiquité

26 | 2017

Varia

\section{Molly SWETNAM-BURLAND, Egypt in Italy. Visions of Egypt in Roman Imperial Culture}

\section{Laurent Bricault}

\section{OpenEdition}

\section{Journals}

Édition électronique

URL : http://journals.openedition.org/anabases/6272

DOI : 10.4000/anabases. 6272

ISSN : 2256-9421

\section{Éditeur}

E.R.A.S.M.E.

\section{Édition imprimée}

Date de publication : 1 novembre 2017

Pagination : 251-253

ISSN : 1774-4296

\section{Référence électronique}

Laurent Bricault, « Molly swetnam-BuRland, Egypt in Italy. Visions of Egypt in Roman Imperial Culture », Anabases [En ligne], 26 | 2017, mis en ligne le 01 novembre 2017, consulté le 20 janvier 2021. URL: http://journals.openedition.org/anabases/6272 ; DOI : https://doi.org/10.4000/anabases.6272

Ce document a été généré automatiquement le 20 janvier 2021.

(c) Anabases 


\title{
Molly SWETNAM-BURLAND, Egypt in Italy. Visions of Egypt in Roman Imperial Culture
}

\author{
Laurent Bricault
}

\section{RÉFÉRENCE}

Molly SWETNAM-BURLAND, Egypt in Italy. Visions of Egypt in Roman Imperial Culture, New York, Cambridge University Press, 2015, XII + 249 p., 110 dollars / ISBN

978-1-107-04048-9.

Ce livre est issu de la thèse soutenue par M. S.-B. en 2002 à l'université du Michigan. Ces dernières années, certaines parties de sa dissertation ont paru sous la forme d'articles, que l'on retrouve toutefois dans les deuxième et quatrième chapitres. Si l'on ajoute à ce constat les nombreux travaux conduits depuis plus d'une décennie sur ces questions, et qui ont profondément fait évoluer ce que l'on pouvait en dire au $\mathrm{xx}^{\mathrm{e}}$ siècle, le volume objet de la présente recension peut apparaître en 2015 moins novateur qu'il aurait pu l'être au début des années 2000. Il semble cependant que l'auteur ait largement puisé dans l'abondante littérature récente sans se limiter, comme trop souvent chez les jeunes savants anglo-saxons, aux publications de langue anglaise, même si l'on peut s'interroger, à la lecture de tel ou tel chapitre, s'il faut, lors de la consultation de la riche bibliographie des p. 217-245, prendre au mot l'expression «works cited or consulted» du bas de la p. 217, ou le «works cited and consulted» qui ouvre cette même page.

Notons d'emblée que cet ouvrage, qui ne s'appuie sur aucun catalogue documentaire, ne peut prétendre au titre de synthèse sur le sujet qui est le sien, comme nous le verrons. Après une introduction (p.1-17) dans laquelle l'auteur présente de manière descriptive le contexte historique et culturel de son étude, celle des images et, dans une bien moindre mesure, des textes relatifs à l'Égypte dans l'Italie des époques julio- 
claudienne et flavienne, quatre chapitres suivent, avant une très brève conclusion (p. 182-185).

Dans le premier chapitre (p. 18-64), sans doute le meilleur du livre, M. S.-B. brosse un tableau à facettes multiples des objets égyptiens ou égyptisants retrouvés en contexte en Italie, avec toute la précision souhaitée. Le chapitre 2 (p. 65-104) se concentre sur les deux obélisques, aujourd'hui érigés Piazza del Popolo et devant le Palazzo Montecitorio, qu'Auguste fit transporter à Rome en 10/9 av. J.-C. pour les intégrer dans l'exposition visuelle et urbaine de son programme politique et culturel. Le chapitre 3 (p. 105-141) se focalise sur l'Iséum de Pompéi, son programme décoratif et le discours qu'il suggère de la part de ses commanditaires. Le quatrième chapitre (p. 142-181) s'attache à l'analyse des images de l'Égypte chez les Romains, à partir de trois études de cas, les nilotica, les statues du Nil et du Tibre aujourd'hui aux musées du Vatican et du Louvre, enfin la quinzième satire de Juvénal.

Si nombre de remarques sont bienvenues, l'ouvrage peine toutefois à emporter l'adhésion. La première difficulté concernant le sujet étudié réside dans la décontextualisation d'un nombre considérable de monuments, mis au jour pour la plupart entre la Renaissance et le $\mathrm{XIX}^{\mathrm{e}}$ siècle. M. S.-B. en a parfaitement conscience et choisit pour cela de focaliser son attention sur quelques cas d'étude spécifiques localisés pour l'essentiel à Rome et Pompéi, ce que l'on ne pourra que regretter. La quinzième satire de Juvénal illustre-t-elle « l'attitude des Romains » ou bien la position défensive d'un auteur singulier, Juvénal, vis-à-vis de l'Égypte et de son cortège d'excentricités barbares ? Les statues du Nil et du Tibre sont-elles caractéristiques d'un mouvement qui touche toute l'Italie durant le premier siècle du principat, ou bien simplement d'un contexte précis qui les a peut-être vues s'ériger dans le cadre de l'Iséum du Champ de Mars à l'époque flavienne ? Au-delà de l'analyse, aussi bien menée soit elle, d'un monument de pierre ou de papier, c'est la question de la pertinence globale de l'enquête qui se pose. Le monde impérial romain était polysémique, divers, multiple et évolutif. Les champs sémantiques s'y déplacent avec le temps, mais aussi dans l'espace et la société. Tel relief façonné en Égypte au IV ${ }^{\mathrm{e}} \mathrm{s}$. av. J.-C. pour figurer sur les parois du temple d'Isis de Behbeit el-Hagar et transporté à Rome aux premiers temps du principat pour prendre place dans l'Iséum du Champ de Mars doit être interrogé à plusieurs niveaux : que représente-t-il pour ceux qui l'ont commandité à l'origine, pour ceux qui l'ont créé, pour ceux qui ont choisi de le faire venir à Rome, pour ceux encore qui l'ont eu sous les yeux durant l'Empire? Le savoir, la culture, les référents de chacun sont importants et doivent être pris en considération. Même s'ils ne nous sont pour l'essentiel pas accessibles, la question mérite d'être posée. Ériger un obélisque sur la spina d'un cirque romain est signifiant pour le princeps et le discours idéologique qui est le sien, mais qu'en est-il de la perception de cet obélisque par ceux qui viennent au spectacle? Et par les successeurs, proches ou lointains, du prince, dont certains, un jour, coifferont le pyramidion d'une croix?

Sans doute la période prise en considération par l'auteur est-elle trop restreinte, comme l'est assurément l'espace géographique de l'étude, qui se limite essentiellement à Rome et aux cités vésuviennes. Bien d'autres situations auraient mérité d'être intégrées à la réflexion: le dossier flavien qui entoure l'« Iséum " de Bénévent, le complexe augustéen puis antonin du sanctuaire isiaque d'Industria, Aquilée, Vérone et leurs dizaines de documents. Le titre du livre s'avère, à la lecture, quelque peu trompeur à bien des égards. L'Italie des premiers temps du principat n'était pas 
homogène, ni géographiquement, ni socialement, ni culturellement et l'analyse, fût-elle riche et méthodique, de quelques monuments ne peut suffire à rendre compte du sujet envisagé. Et ce d'autant plus que l'Égypte ne l'était guère davantage après trois siècles de domination gréco-macédonienne. Il n'est pas sûr qu'à l'époque julio-claudienne et au début du principat flavien, l'Isis accueillie en Italie depuis au moins la fin du II $\mathrm{e}$ s. av. J.-C. l'ait été en qualité de déesse égyptienne ni pour ses qualités d'Égyptienne. Sans doute aurait-il été plus judicieux d'étudier, en une analyse comparée assurément fructueuse, les différentes réceptions italiennes d'Isis (à Rome, à Pompéi, à Bénévent, ailleurs encore), en les contextualisant historiquement et celles de Sarapis, alexandrin, grec et/ou égyptien. Et s'interroger: pour qui et pourquoi? Ce livre, malgré ses indéniables qualités, ne répond pas à ces questions. Pourquoi ces monuments, ces objets, ces idées, anciens ou récents, authentiques ou adaptés, recréés ou nouveaux, investissent-ils l'espace culturel et politique de l'Italie impériale?

Et, d'ailleurs, ce qui est égyptien ou égyptisant pour nous, historiens du xxI ${ }^{\mathrm{e}}$ s. bardés de concepts mais - heureusement serais-je tenté de dire - incapables de se mettre d'accord sur une commune définition, l'était-il pour « les Romains » en général ? Pour ceux d'Aquilée ou de Syracuse comme pour ceux de Rome et de Pompéi ? Pour ceux de Pouzzoles auI ${ }^{\text {er }}$ s. av. J.-C. comme pour ceux d'Ostie au II ${ }^{\mathrm{e}}$ s. apr. J.-C. ? Pour certains Romains plus au fait des réalités artistiques, artisanales ou historiques que d'autres moins avertis? Lorsque Jeff Beck, Rod Stewart ou Led Zeppelin interprétaient You shook me en 1968, l'auditeur italien (ou allemand, ou français) était-il conscient d'avoir affaire à des musiciens britanniques interprétant - le mot est fondamental - un classique du blues de Chicago composé en 1962 par Willie Dixon et J. B. Lenoir, et chanté par Muddy Waters? Ou bien notre volonté cartésienne et parfois très artificielle de distinguer en grands schémas explicatifs faisant fi des multiples réalités est-elle anachronique et inadaptée, en partie parce que ces monuments et ces productions appartenaient à une sorte de koine classique au sein de laquelle éléments égyptiens, grecs et autres s'étaient déjà rencontrés avant même que Rome ne fasse la conquête de la Méditerranée orientale? En d'autres termes, l'égyptomanie italienne (romaine ?) se limitait-elle à une sorte de fascination d'antiquaire pour le lointain et exotique passé du puissant royaume de Pharaon, ou bien doit-elle s'envisager à plusieurs autres degrés de réception sinon d'imprégnation, notamment avec l'Égypte munificente, raffinée et ostentatoire des Gréco-macédoniens, en fonction de variables politiques, sociales, géographiques et historiques? Avec ce livre, M. S.-B. nous offre un ouvrage agréable à lire, stimulant, qui invite à élargir la réflexion. Il est fort bien mis en page, quasiment exempt de coquilles et pourvu d'une illustration de qualité quoique assez convenue, dont huit planches en couleurs se rapportant presque toutes à la seule zone pompéienne. 


\section{AUTEUR}

\section{LAURENT BRICAULT}

Université Toulouse - Jean Jaurès (UT2J)

bricault@univ-tlse2.fr 